Check for updates

Cite this: RSC Adv., 2018, 8, 6027

Received 3rd November 2017

Accepted 22nd January 2018

DOI: $10.1039 / c 7 r a 12097 d$

rsc.li/rsc-advances

\section{Microwave-assisted hydrothermal synthesis of chrysanthemum-like Ag/ZnO prismatic nanorods and their photocatalytic properties with multiple modes for dye degradation and hydrogen production}

\begin{abstract}
Zichan Xin, $^{\text {ab }}$ Li Li, (D)*ab Xiuli Zhang ${ }^{b}$ and Wenzhi Zhang ${ }^{b}$
A series of $\mathrm{Ag} / \mathrm{ZnO}$ composites were prepared by microwave-assisted hydrothermal synthesis. Their composition, structure, and morphology were well characterized by X-ray diffraction (XRD), UV-visible diffuse reflectance spectroscopy (UV-vis/DRS), X-ray photoelectron spectroscopy (XPS), scanning electron microscopy (SEM), and $\mathrm{N}_{2}$ adsorption-desorption analyses. The results showed that the microwave-assisted synthesis method did not significantly alter the crystal structure of the composites. However, light absorption by the composite was clearly enhanced, its Brunauer-Emmett-Teller surface area values changed, and excellent surface morphology was observed. Moreover, the Ag/ZnO composite formed via microwave-assisted hydrothermal synthesis exhibited more regular stacking piled into a chrysanthemum-like structure. Under ultraviolet, visible-light, simulated sunlight, and microwaveassisted irradiation, the composite exhibited better photocatalytic properties for the photocatalytic degradation of rhodamine B compared to that of P25 and $\mathrm{ZnO}$. Moreover, the composite was investigated as a catalyst for the degradation of four dyes with different structures under UV conditions, exhibiting good degradation performance. Furthermore, the degradation efficiency did not change significantly after three cycles, indicating a certain degree of stability. In addition, the photocatalytic hydrogen production experiments showed that the nanocomposite $\mathrm{Ag} / \mathrm{ZnO}$ had some ability to produce photocatalytic hydrogen.
\end{abstract}

\section{Introduction}

Currently, the photocatalytic degradation of organic pollutants via semiconductors has been beneficial for the environmental purification. ${ }^{1-4}$ Photocatalytic technology can effectively degrade or completely mineralize common organic compounds without secondary pollution. Moreover, photocatalysts such as $\mathrm{TiO}_{2}$, a type of environmentally friendly catalyst, has many advantages owing to its simple structure, easily controllable operating conditions, strong oxidizing ability, and economic and environmental benefits.,

Simultaneously, the photocatalytic generation of hydrogen is one of the most promising routes to use this abundant energy for environment-friendly and clean technologies. However, the main problems hindering the use of photocatalytic technology are low catalytic efficiency, caused by the low light utilization rate and the high recombination rate of the photogenerated

${ }^{a}$ College of Materials Science and Engineering, Qiqihar University, Qiqihar 161006, PR China. E-mail: qqhrll@163.com; qqhrlili@126.com; Tel: +8604522738206

${ }^{b}$ College of Chemistry and Chemical Engineering, Qiqihar University, Qiqihar 161006, PR China electron-hole pairs. ${ }^{7}$ The photocatalytic activity of semiconductors can be enhanced by changing the preparation method for different particle size and/or morphology.

In recent years, microwave synthesis has been favored by most researchers because of its rapid and simple procedure. ${ }^{8}$ Microwave synthesis can often optimize the morphology of the products, thus improving the various properties of the material. Because of the different absorptive capacity of the material, in the process of microwave reaction, the degree of heating of the material is different. For highly polar molecules, the friction between them will increase. Microwaves exhibit the characteristics of penetration, low thermal inertia and selective heating. Compared to other methods, microwave synthesis has unique advantages such as selective heating, fast heating speed, high reaction efficiency, and low energy consumption; therefore, it is widely used in the preparation of semiconductor composite materials. ${ }^{9-11}$ For example, Wu et al. prepared MWCNTs wrapped with a uniform and small diameter of ZnS nanospheres using microwave irradiation, ${ }^{12}$ and Pal et al. fabricated Au-decorated $\mathrm{ZnO}$ nanorods with excellent photocatalytic activities via microwave-assisted synthesis. ${ }^{13}$ Moreover, the light utilization rate can also be improved by 
doping noble metals, transition metals, or nonmetallic elements to inhibit the recombination of the photogenerated electron-hole pairs or change its band structure. Among the above mentioned methods, doping is an effective tool to improve the photocatalytic activity of semiconductors. In particular, transition metals such as platinum, silver, and iron could improve charge transfer by trapping the photoinduced charge carriers, thus enhancing the performance of photochemical degradation. ${ }^{\mathbf{1 4 - 1 6}}$

At present, many types of photocatalysts such as $\mathrm{ZnO}$ and $\mathrm{TiO}_{2}$ are used for photocatalytic oxidation. Zinc oxide is a type II-VI semiconductor with a direct band gap of $3.37 \mathrm{eV}$ at room temperature and a large exciton binding energy of $\sim 60 \mathrm{meV} .{ }^{17}$ Because of its chemical stability, abundance of raw materials for its preparation, and cost effectiveness, zinc oxide has been widely used as a catalytic material. However, some issues such as light corrosion in the ultraviolet region, poor light stability, wide band gap, and the exclusive use of ultraviolet excitation are of concern. Therefore, in this study, the noble metal $\mathrm{Ag}$ was doped into the semiconductor $\mathrm{ZnO}$ material using microwave-assisted hydrothermal synthesis. Due to the surface plasmon resonance (SPR) of noble metal nanoparticles, we hypothesized that $\mathrm{Ag}$ can change the electron conducting manner to some extent, reduce the recombination rate of the photogenerated electron-hole pairs and improve the efficiency of the photocatalytic reaction. In contrast, the unique polarization effect of microwaves was expected to improve the morphology and particle distribution of the synthesized products and thus, possibly improve the photocatalytic activity of the $\mathrm{Ag} / \mathrm{ZnO}$ composite. Moreover, a series of $\mathrm{Ag} / \mathrm{ZnO}$ composite materials were prepared under different microwave irradiation times to investigate the effect of microwave irradiation time on the physiochemical properties of the product. The photocatalytic conditions of the $\mathrm{Ag} / \mathrm{ZnO}$ degradation dye rhodamine $\mathrm{B}$ and photocatalytic hydrogen production were studied under different photocatalytic conditions to obtain better experimental results.

\section{Experimental section}

\subsection{Reagents and instruments}

Zinc acetate dehydrate $\left(\mathrm{Zn}\left(\mathrm{CH}_{3} \mathrm{COO}\right)_{2} \cdot 2 \mathrm{H}_{2} \mathrm{O}\right)$ and silver nitrate $\left(\mathrm{AgNO}_{3}\right)$ were purchased from Tianjin Kermel Co. Ltd. Sodium peroxide was purchased from Tianjin Dagu of Plastic Manufacturing Co. Ltd. Dyes were purchased from the Beijing chemical plant. All chemicals were of analytical grade (AR) and used without further purification. Secondary distilled water was employed for all experiments. Microwave synthesis was performed using a MDS-8G microwave reactor (Shanghai SINEO Microwave Chemical Technology Co. Ltd.). Photochemical investigations were performed using a BL-GHX-V photochemical reaction instrument (Xi'an Biological Technology Co. LTD). Absorbance spectra were recorded using a TU-1901 UV-vis double beam spectrophotometer (UV-vis, Beijing Purkinje General Company).

\subsection{Synthesis}

In a typical process, $\mathrm{Zn}\left(\mathrm{CH}_{3} \mathrm{COO}\right)_{2} \cdot 2 \mathrm{H}_{2} \mathrm{O}, \mathrm{Na}_{2} \mathrm{O}_{2}$, and $\mathrm{AgNO}_{3}$ were dissolved in $40 \mathrm{~mL}$ isopropanol solution in a molar ratio of $1: 1.5: 0.05$ for CTAB : $\mathrm{Zn}: \mathrm{Ag}$. The resultant reaction mixture was stirred for $30 \mathrm{~min}$ to mix thoroughly and then transferred to a Teflon-lined stainless autoclave heated at $200{ }^{\circ} \mathrm{C}$. The reaction mixture was subjected to microwave irradiation for $3,4.5$, and $6 \mathrm{~h}$ at $300 \mathrm{~W}$. The reaction mixtures were removed, washed, filtered, dried at $80{ }^{\circ} \mathrm{C}$, and calcined at $300{ }^{\circ} \mathrm{C}$ for $2 \mathrm{~h}$ and the products were named $\mathrm{Ag} / \mathrm{ZnO}-3 \mathrm{~h}, \mathrm{Ag} / \mathrm{ZnO}-4.5 \mathrm{~h}$ and $\mathrm{Ag} / \mathrm{ZnO}-6 \mathrm{~h}$, respectively. The sample for the comparison was labeled $\mathrm{ZnO}$, which was prepared under the same conditions by heating at $200{ }^{\circ} \mathrm{C}$ under microwave irradiation for $3 \mathrm{~h}$ at $300 \mathrm{~W}$, and calcined at $300{ }^{\circ} \mathrm{C}$ for $2 \mathrm{~h}$.

\subsection{Characterizations}

X-ray diffraction (XRD) patterns were collected on a Bruker-AXS D8 X-ray diffractometer equipped with $\mathrm{CuK} \alpha$ radiation. X-ray photoelectron spectra were recorded using a VG-ADES400X spectrometer as the excitation source and the degree of vacuum was $1 \times 10^{-8} \mathrm{~Pa}$. The microstructure was examined by high-resolution transmission electron microscopy (HR-TEM) (JEM-2100F) operated at $200 \mathrm{kV}$. The SEM-EDS of the sample was analyzed using a Hitachi S-4700 scanning electron microscope at a working voltage of $5 \mathrm{kV}$. The optical absorbance spectra of the as-prepared samples were recorded on a UV-vis spectrophotometer (TU-1901) equipped with a diffuse reflectance accessory using $\mathrm{BaSO}_{4}$ as the reflectance standard. The microstructure and morphology of the products were characterized using an S-4700 scanning electron microscope (Japan) operated at $5 \mathrm{kV}$. The Brunauer-Emmett-Teller (BET) surface areas, pore volumes (VP) and the distribution of pore size were derived from the nitrogen adsorption at $77 \mathrm{~K}$ using a Quantachrome Nova Win II instrument.

\subsection{Multi-mode photocatalysis experiment}

The photocatalytic device consisted of a cylindrical glass tube and built-in light source surrounding a quartz sleeve. Ultraviolet light was irradiated using a $125 \mathrm{~W} \mathrm{Hg-lamp} \mathrm{with} \mathrm{a} \mathrm{maximum}$ emission at $\sim 313.2 \mathrm{~nm}$; visible light was obtained using a $400 \mathrm{~W}$ Xe lamp with the main emission lines at $>410 \mathrm{~nm}$. The simulated sunlight source was irradiated using a $1000 \mathrm{~W}$ Xe-lamp with emission from strong UV to near IR consecutive spectra ( 300-1050 $\mathrm{nm}$ ); the distance between the lamp and reaction liquid was $8.5 \mathrm{~cm}$. A microwave discharge electrodeless lamp (MDEL) with $\mathrm{H}$ shape model and a power of $15 \mathrm{~W}$ with a maximum emission at $\sim 280 \mathrm{~nm}$ was used for the microwaveassisted test. The output power of the microwave was $\sim 600 \mathrm{~W} \cdot{ }^{\mathbf{1 6}}$ In a typical reaction under UV light and simulated sunlight, $90 \mathrm{~mL}$ of the aqueous RhB solution $\left(50 \mathrm{mg} \mathrm{L}^{-1}\right)$ and $0.15 \mathrm{~g}$ of the photocatalyst powder was mixed in a quartz photoreactor. For the experiments under visible light, $220 \mathrm{~mL}$ of the aqueous $\mathrm{RhB}$ solution $\left(50 \mathrm{mg} \mathrm{L}^{-1}\right)$ and $0.3 \mathrm{~g}$ of the photocatalyst powder were mixed in a quartz photoreactor. For the microwave-assisted irradiation, $500 \mathrm{~mL}$ of the aqueous $\mathrm{RhB}$ solution $\left(50 \mathrm{mg} \mathrm{L}^{-1}\right)$ 
and $0.5 \mathrm{~g}$ of the photocatalyst powder were mixed in a quartz photoreactor. During the photocatalytic process under light irradiation, the suspensions were kept at constant temperature $\left(20 \pm 5{ }^{\circ} \mathrm{C}\right)$ by placing the lamp with jacket into the interior of the reaction suspensions or by means of circulating the solutions to a cooler using a peristaltic pump.

Photocatalytic reaction. In each test, the catalyst was dispersed in organic pollutants ( $\mathrm{RhB}, C_{0}=50 \mathrm{mg} \mathrm{\textrm {L } ^ { - 1 }}$ ) by ultrasonic dispersion for $\sim 10 \mathrm{~min}$. Prior to irradiation, the suspension was magnetically stirred in the dark for $30 \mathrm{~min}$ to achieve absorbance-desorbance equilibrium. The solution was stirred vigorously during the photocatalytic reaction and $3 \mathrm{~mL}$ aliquots were collected at selected time intervals and centrifuged to remove the photocatalyst powders. Then, the quantitative dilution was carried out. The concentration of RhB in the photocatalytic reaction was analyzed using a UV-vis spectrophotometer at $554 \mathrm{~nm}$ wavelength.

\subsection{Photocatalytic hydrogen production experiment}

Photocatalytic hydrogen production was carried out in a vacuum reactor connected to a closed circulatory system (lab solar-III AG system). Initially, $100 \mathrm{mg}$ of photocatalyst was dispersed in $50 \mathrm{~mL}$ of distilled water and $3.0 \mathrm{~g}$ of $\mathrm{Na}_{2} \mathrm{~S} \cdot \mathrm{H}_{2} \mathrm{O}$ and $2.2 \mathrm{~g}$ of $\mathrm{Na}_{2} \mathrm{SO}_{3}$ were added as sacrificial agents. After the vacuum degassing treatment, the light was tested under the condition of stirring for the photocoagulation of water. A $300 \mathrm{~W}$ xenon lamp was used as the light source fixed at $10 \mathrm{~cm}$ from the reaction solution. High purity nitrogen was used as the carrier gas at a flow rate of $0.5 \mathrm{~mL} \mathrm{~s}^{-1}$. The reaction was carried out with an output pressure of $0.4-0.5 \mathrm{MPa}$, and an operating voltage and an operating current of about $20 \mathrm{mV}$ and $50 \mathrm{~mA}$, respectively. During the reaction, circulating cooling water maintained the temperature of the reactor at about $5{ }^{\circ} \mathrm{C}$. The gas of the hydrogen production process was collected and analyzed by gas chromatography. The hydrogen production was calculated according to the peak area of different reaction time, and the catalytic activity of the catalyst was measured by the total hydrogen production time of $8 \mathrm{~h}$.

\section{Results and discussion}

\subsection{XRD analysis}

The crystal structures of the obtained $\mathrm{Ag} / \mathrm{ZnO}$ products were investigated by XRD; the results are shown in Fig. 1. Pure Ag has a cubic crystal structure, as shown in Fig. 1, and the visible characteristic diffraction peaks appear primarily at the $2 \theta$ values of $38.21^{\circ}, 44.47^{\circ}, 64.47^{\circ}$, and $77.48^{\circ}$ (JCPDS03-0921). Pure ZnO has a wurtzite structure with its characteristic diffraction peaks located primarily at the $2 \theta$ diffraction angle values of $31.7^{\circ}$, $34.4^{\circ}, 36.2^{\circ}, 47.5^{\circ}, 56.5^{\circ}, 62.8^{\circ}, 66.4^{\circ}, 68.1^{\circ}$, and 69.2 ${ }^{\circ}$ (JCPDS361451). Moreover, the XRD spectra of a series of $\mathrm{Ag} / \mathrm{ZnO}$ composites retained the characteristic peaks for $\mathrm{ZnO}$ and $\mathrm{Ag}$, indicating that $\mathrm{Ag}$ and $\mathrm{ZnO}$ in the $\mathrm{Ag} / \mathrm{ZnO}$ composites have the cubic phase and wurtzite structures, respectively. These results indicated that the change in microwave irradiation times had no effect on the crystal type of $\mathrm{Ag} / \mathrm{ZnO}$. Moreover, the sharp

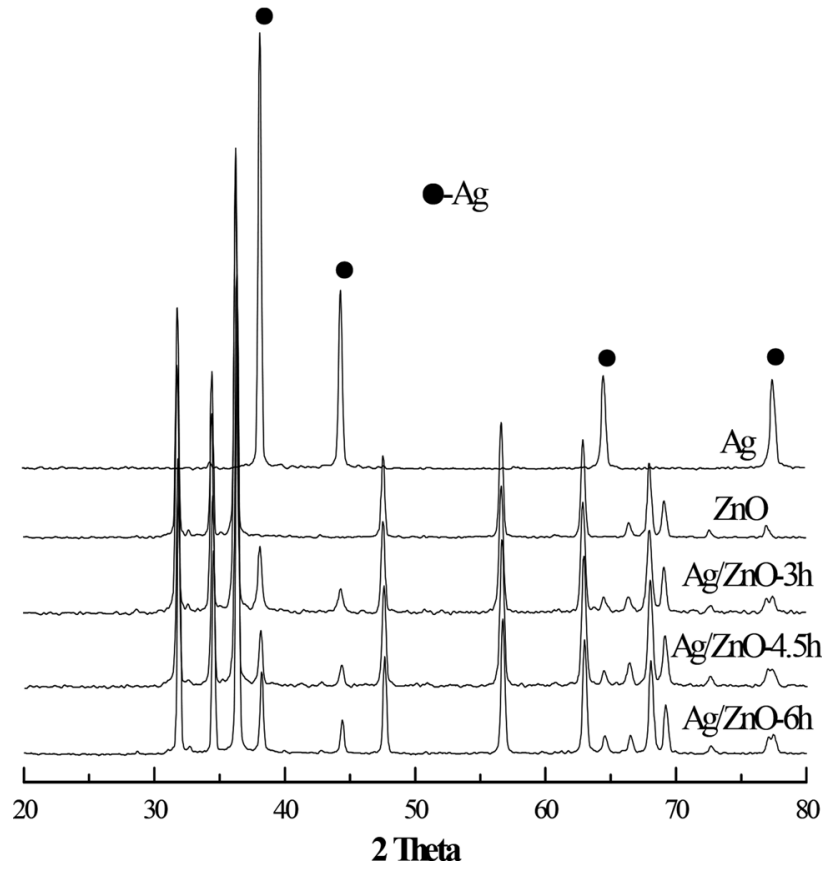

Fig. 1 XRD patterns of $\mathrm{Ag}, \mathrm{ZnO}, \mathrm{Ag} / \mathrm{ZnO}-3 \mathrm{~h}, \mathrm{Ag} / \mathrm{ZnO}-4.5 \mathrm{~h}$, and $\mathrm{Ag} /$ ZnO-6h.

peaks of Ag/ZnO samples indicated a better crystallization of the synthesized product.

Furthermore, Fig. 1 shows that the diffraction peak intensity of each substance in the microwave-assisted synthesis of $\mathrm{Ag} / \mathrm{ZnO}-6 \mathrm{~h}$ was slightly stronger than that of each material in the other composite materials, indicating that the extended microwave radiation time was helpful in improving the crystal structure of the samples. ${ }^{18}$ The cubic structure of $\mathrm{Ag}$ in $\mathrm{Ag} / \mathrm{ZnO}-$ $6 \mathrm{~h}$ was found to be superior to those of other composite materials as shown in Fig. 1 and the photocatalytic activity was expected to be better than those of the composites synthesized for different times.

Furthermore, the crystallite sizes of each of the synthesized products were calculated using the Scherrer equation: $D_{\mathrm{c}}=0.89 \lambda /$ $(B \cos \theta)(\lambda$ is the wavelength of the $\mathrm{X}$-ray; $B$ is the half-width of the diffraction peak; $\theta$ is the diffraction angle), as summarized in Table 1 , indicating that the crystallite size of each $\mathrm{Ag} / \mathrm{ZnO}$ composite decreased significantly compared to that of $\mathrm{ZnO}$ and the decrease can be attributed to doping with the noble metal Ag.

Table 1 Crystallite sizes $\left(D_{\mathrm{c}}\right)$, energy band gaps $\left(E_{\mathrm{g}}\right)$, BET surface areas $\left(S_{\mathrm{BET}}\right)$, average pore diameters $(D)$, and pore volumes $\left(V_{\text {total }}\right)$ of $\mathrm{ZnO}$ and $\mathrm{Ag} / \mathrm{ZnO}$ composites $^{a}$

\begin{tabular}{lcclll}
\hline Sample & $D_{\mathrm{c}} / \mathrm{nm}$ & $E_{\mathrm{g}} / \mathrm{eV}$ & $S_{\mathrm{BET}} /\left(\mathrm{m}^{2} \mathrm{~g}^{-1}\right)$ & $D / \mathrm{nm}$ & $V_{\text {total }} /\left(\mathrm{cm}^{3} \mathrm{~g}^{-1}\right)$ \\
\hline $\mathrm{ZnO}$ & 47.0 & 3.21 & 1.05 & 4.1 & 0.004 \\
$\mathrm{Ag} / \mathrm{ZnO}-3 \mathrm{~h}$ & 40.4 & 3.17 & 6.71 & 3.3 & 0.014 \\
$\mathrm{Ag} / \mathrm{ZnO}-4.5 \mathrm{~h}$ & 43.1 & 3.14 & 6.40 & 3.2 & 0.030 \\
$\mathrm{Ag} / \mathrm{ZnO}-6 \mathrm{~h}$ & 44.0 & 3.12 & 6.74 & 3.4 & 0.029
\end{tabular}

${ }^{a} D_{\mathrm{c}}$ is the crystallite sizes. 
Moreover, the crystallite size of each $\mathrm{Ag} / \mathrm{ZnO}$ increased significantly with an increase in microwave irradiation time, indicating that microwave irradiation promotes the growth of grains. ${ }^{19}$

\subsection{UV-vis diffuse reflectance spectra analysis}

The light absorption characteristics of $\mathrm{Ag} / \mathrm{ZnO}$ composites were characterized by UV-vis diffuse reflectance spectroscopy (Fig. 2). Fig. 2a shows that the synthesized $\mathrm{Ag} / \mathrm{ZnO}$ composites had strong absorption both in the ultraviolet and visible regions. The broad absorption in the visible region is due to the surface plasmon resonance (SPR) of Ag nanoparticles in the product. ${ }^{20}$ In contrast, the strong polarization effects of the microwave irradiation resulted in further aggregation of the Ag nanoparticles, thus enhancing the absorption of the synthesized $\mathrm{Ag} / \mathrm{ZnO}$ composites in the visible region, predicting that the synthesized products $\mathrm{Ag} / \mathrm{ZnO}$ will have some visible-light activity. Moreover, the intensity of the optical absorption of the composite materials gradually increased on increasing the microwave irradiation time, indicating that the extended microwave radiation time was helpful to the optical absorption of the products. Fig. $2 \mathrm{~b}$ shows the plot of $(\alpha h \nu)^{2}$ versus energy $(h \nu)$; the relation between the absorption coefficient $\alpha$ and the photon energy $h \nu$ is $(\alpha h \nu)^{2}=K\left(h \nu-E_{\mathrm{g}}\right)$, where parameter $K$ is associated with the valence band and conduction band and $E_{\mathrm{g}}$ is the optical energy gap between the valence and conduction band. ${ }^{21}$ The calculated $E_{\mathrm{g}}$ values of $\mathrm{ZnO}, \mathrm{Ag} / \mathrm{ZnO}-3 \mathrm{~h}, \mathrm{Ag} / \mathrm{ZnO}-$ $4.5 \mathrm{~h}$, and $\mathrm{Ag} / \mathrm{ZnO}-6 \mathrm{~h}$ are listed in Table 1 . The $E_{\mathrm{g}}$ values of each product, as listed in Table 1 , show that the band gap energies of the $\mathrm{Ag} / \mathrm{ZnO}-6 \mathrm{~h}$ composite was slightly lower than those of the other samples, indicating that $\mathrm{Ag} / \mathrm{ZnO}-6 \mathrm{~h}$ may have better photocatalytic activity.

\subsection{XPS analysis}

XPS analysis was performed to investigate the surface elemental composition and chemical state for a series of $\mathrm{Ag} / \mathrm{ZnO}$ samples; the results are shown in Fig. 3. There were primarily four types of elements, which are $\mathrm{Ag}, \mathrm{Zn}, \mathrm{O}$, and $\mathrm{C}$, on the composite surface as shown in Fig. 3a. The presence of $\mathrm{C}$ was ascribed to the adventitious hydrocarbon from the XPS instrument. Fig. 3b shows that the binding energies of $\mathrm{Ag} 3 \mathrm{~d}_{5 / 2}$ and $\mathrm{Ag} 3 \mathrm{~d}_{3 / 2}$ for $\mathrm{Ag} / \mathrm{ZnO}-3 \mathrm{~h}$ were 368.2 and $374.2 \mathrm{eV}$, respectively, at the microwave irradiation time of $3 \mathrm{~h}$. The energy spacing of the two lines was $6.0 \mathrm{eV}$, which were the characteristic peaks of the $\mathrm{Ag}$ metal, indicating that $\mathrm{Ag}$ in the product exists in the form of $\mathrm{Ag}^{0} .^{22}$ The binding energy of $\mathrm{Zn} 2 \mathrm{p}_{3 / 2}$ and $\mathrm{Zn} 2 \mathrm{p}_{1 / 2}$ were 1022.3 and $1045.4 \mathrm{eV}$, respectively, indicating that the $\mathrm{Zn}$ in the composite was in the state of $\mathrm{Zn}^{2+}$ (Fig. 3c). ${ }^{23}$ The peak at $531.0 \mathrm{eV}$ corresponds to $\mathrm{O} 1 \mathrm{~s}$, indicating that $\mathrm{O}$ was the lattice oxygen (Fig. 3d). ${ }^{24}$ These results were consistent with the reported XPS data of $\mathrm{Ag} / \mathrm{ZnO}$ composites. The study also found that the peaks of $\mathrm{Ag} 3 \mathrm{~d}_{5 / 2}$ and $\mathrm{Ag} 3 \mathrm{~d}_{3 / 2}, \mathrm{Zn} 2 \mathrm{p}_{3 / 2}$ and $\mathrm{Zn} 2 \mathrm{p}_{1 / 2}$, and $\mathrm{O} 1 \mathrm{~s}$ shifted to lower binding energy with increasing microwave irradiation time, and the shift in the binding energy indicated a strong interaction between metallic $\mathrm{Ag}$ and $\mathrm{ZnO}{ }^{23}$ The binding energy changed with varying microwave irradiation time, indicating that the microwave irradiation time can change the degree of charge transfer between $\mathrm{Ag}$ and $\mathrm{ZnO}$ in the products to some extent. ${ }^{25,26}$ Moreover, the peaks of $\mathrm{Ag}$ in $\mathrm{Ag} / \mathrm{ZnO}-6 \mathrm{~h}$ were extremely sharp and strong and consistent with the XRD results, further indicating that increasing microwave irradiation time was appropriately conducive to the growth of crystals.

\subsection{SEM and TEM analysis}

SEM analysis was performed to investigate the surface morphology of the $\mathrm{Ag} / \mathrm{ZnO}$ composites. Fig. 4 shows the SEM images of $\mathrm{ZnO}$ and $\mathrm{Ag} / \mathrm{ZnO}$ composites, indicating that $\mathrm{ZnO}$ has a regular morphology of six prismatic nanorods in a wide range. However, the prepared $\mathrm{Ag} / \mathrm{ZnO}$ composite materials showed relatively regular nanorods stacked into a chrysanthemum-like structure within a wide range (Fig. 4(e, h and k)). The significantly improved morphology was primarily attributed to the easy formation of $\mathrm{Ag}$ and $\mathrm{ZnO}$ particles with relatively welldefined structure and dispersion owing to strong polarization and high selectivity under microwave radiation. Thus, Ag/ZnO particles were formed with a more regular geometric shape, which was conducive to enhancing the activity of the composite materials to some extent. The reduction of $\mathrm{Ag}^{+}$can be divided into the following steps: first, the rapid formation of nuclei
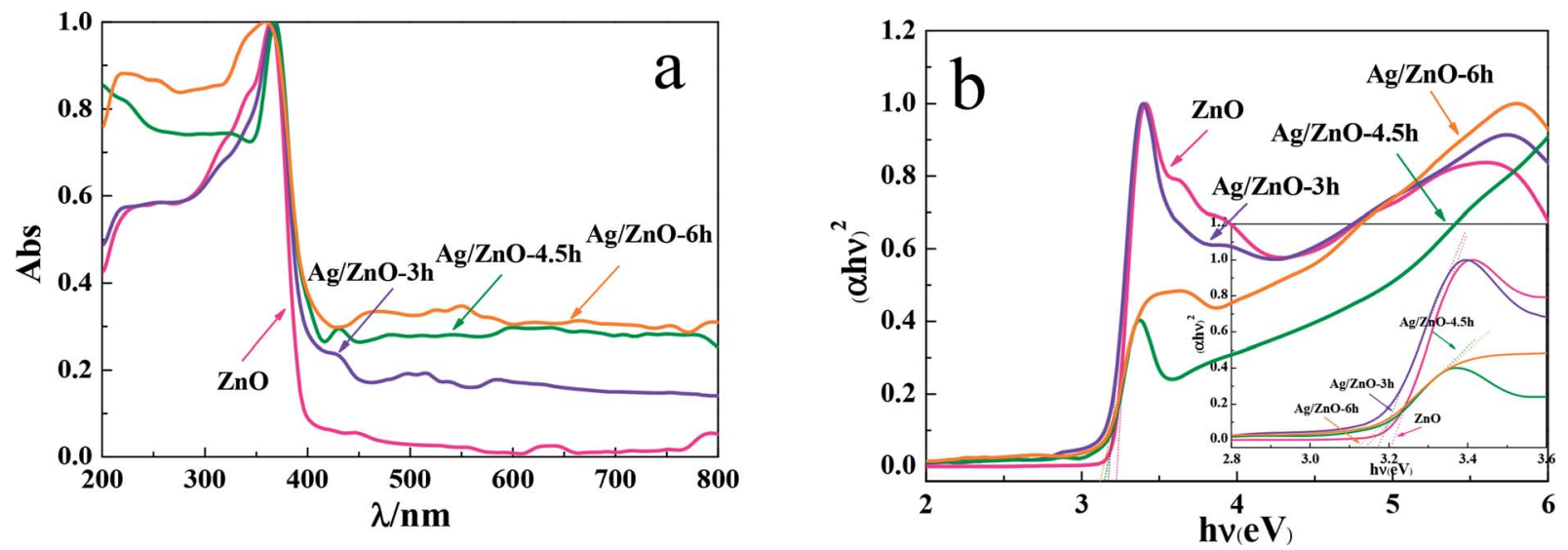

Fig. 2 (a) UV-vis/DRS spectra and (b) plot of $(\alpha h \nu)^{2}$ versus energy $(h \nu)$ of $\mathrm{Ag}, \mathrm{ZnO}, \mathrm{Ag} / \mathrm{ZnO}-3 \mathrm{~h}, \mathrm{Ag} / \mathrm{ZnO}-4.5 \mathrm{~h}$, and $\mathrm{Ag} / \mathrm{ZnO}-6 \mathrm{~h}$. 

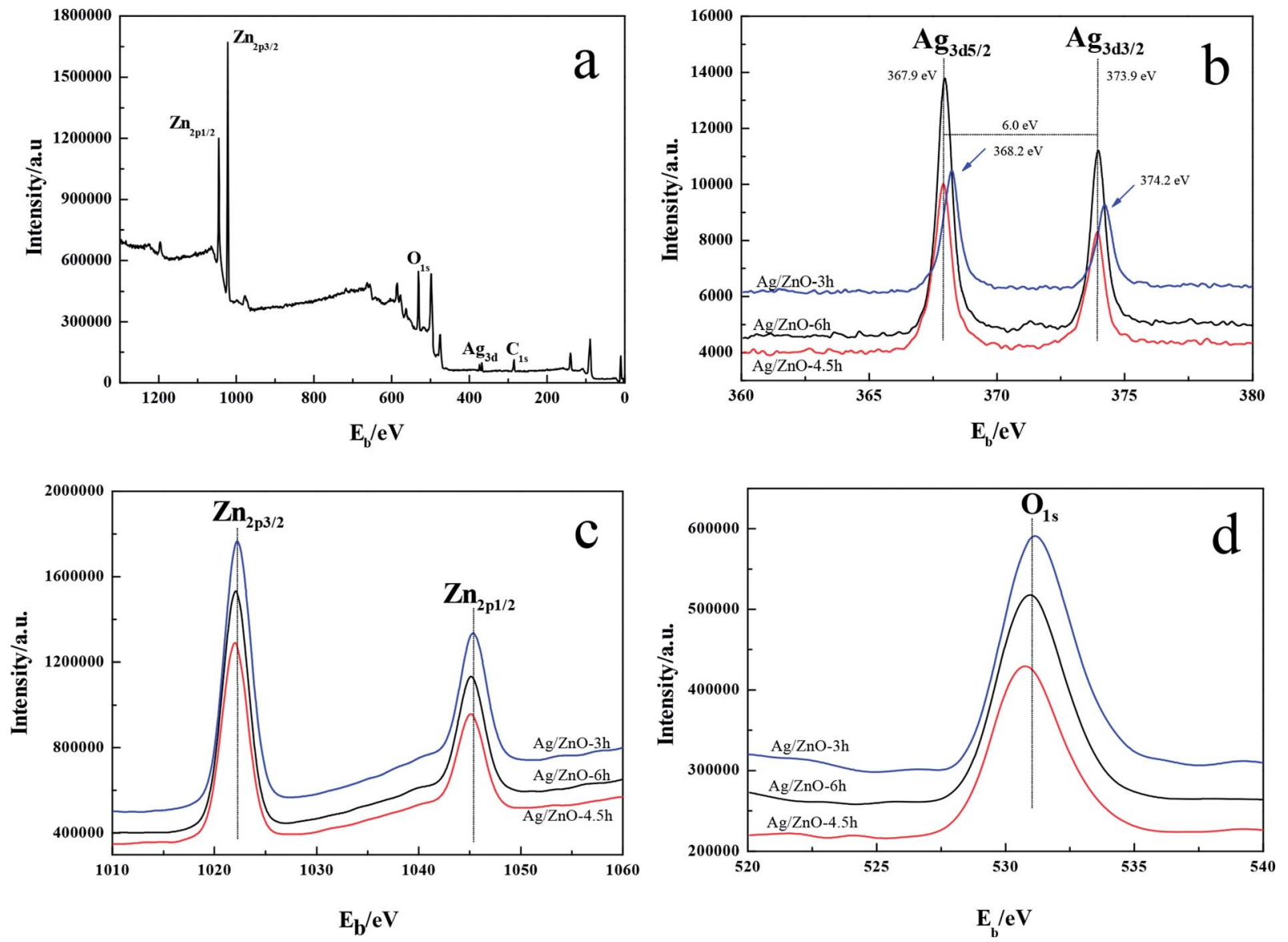

Fig. 3 XPS spectra of Ag/ZnO-6h (a), Ag 3d (b), Zn 2p (c), and O 1s (d).

under microwave irradiation; then, their coalescence or Ostwald ripening into larger particles; subsequently, slow diffusion growth of particles to form the precursor and further coalescence; finally, complete reduction of $\mathrm{Ag}^{+}$and the rapid growth of the particles to their final size. ${ }^{11,27}$ The traditional heating process is slow; however, the microwave heating rate is very fast and the temperature of the reaction mixture reached $200{ }^{\circ} \mathrm{C}$ within $10 \mathrm{~min}$; thus, the overall reaction can be completed in a very short time. Because rapid microwave heating quickly reduced the nuclei of $\mathrm{Ag}$ particles, the effect of microwave irradiation reduced the Ag particles, generating local temperatures around them and prompting $\mathrm{ZnO}$ to reach the desired nuclei temperature to form chrysanthemum-like $\mathrm{Ag} / \mathrm{ZnO}$ composites by stacking and affecting each other (Fig. 4d-l). Moreover, appropriately extending the microwave radiation time was helpful for the aging of the particles and to achieve dense growth. Compared to $\mathrm{Ag} / \mathrm{ZnO}-3 \mathrm{~h}$ (Fig. $4 \mathrm{~d}-\mathrm{f}$ ), $\mathrm{Ag} / \mathrm{ZnO}-4.5 \mathrm{~h}$ stacked more closely and the particle size increased slightly (as shown in Fig. 4g-i). This occurred because microwave irradiation not only promoted the ion diffusion of reactants and decreased the reaction activation energy, but also sufficient microwave radiation time was helpful to the ordered growth of crystals. ${ }^{28}$ Therefore, the morphology of the Ag/ZnO-6h sample was slightly different because of the increased microwave radiation time of 6 h. Fig. 4 j-l shows that the arrangement of the shape was more regular and ordered with decreased volume.

In summary, crystals with different morphology were formed at different irradiation times because the pondermotive force primarily acted at the interfaces and cavities, resulting in rapid growth of the grains and a systematic elimination of the porosity in the microwave field. ${ }^{29}$

To further investigate the morphology of the $\mathrm{Ag} / \mathrm{ZnO}$ composites, HRTEM analysis and element mapping images were carried out; the results are shown in Fig. 5 and 6. According to the HRTEM results, we only found the lattice stripe of the (002) surface of the $\mathrm{ZnO}$ in the composite; the lattice stripe of $\mathrm{Ag}$ was not found..$^{30}$ Therefore, we believe that the formation mechanism of $\mathrm{Ag} / \mathrm{ZnO}$ in this study is consistent with the above situation described in our study. According to the XRD results of the $\mathrm{Ag} / \mathrm{ZnO}$ composite, the existence of the characteristic diffraction peaks of Ag can be clearly observed. Simultaneously, through the characterization of XPS and UVvis/DRS, it is also possible to further prove the existence of Ag in the composite. However, we do not find Ag in the HRTEM image (see Fig. 5) of the $\mathrm{Ag} / \mathrm{ZnO}-6 \mathrm{~h}$ sample. We think the reason is the fact that the size of the composite of our synthetic $\mathrm{Ag} / \mathrm{ZnO}-6 \mathrm{~h}$ is larger and the SEM detection can be seen in the range of about 2.2-2.6 $\mu \mathrm{m}$. Because of the limited range in HRTEM detection, there is no choice for observing such a large 


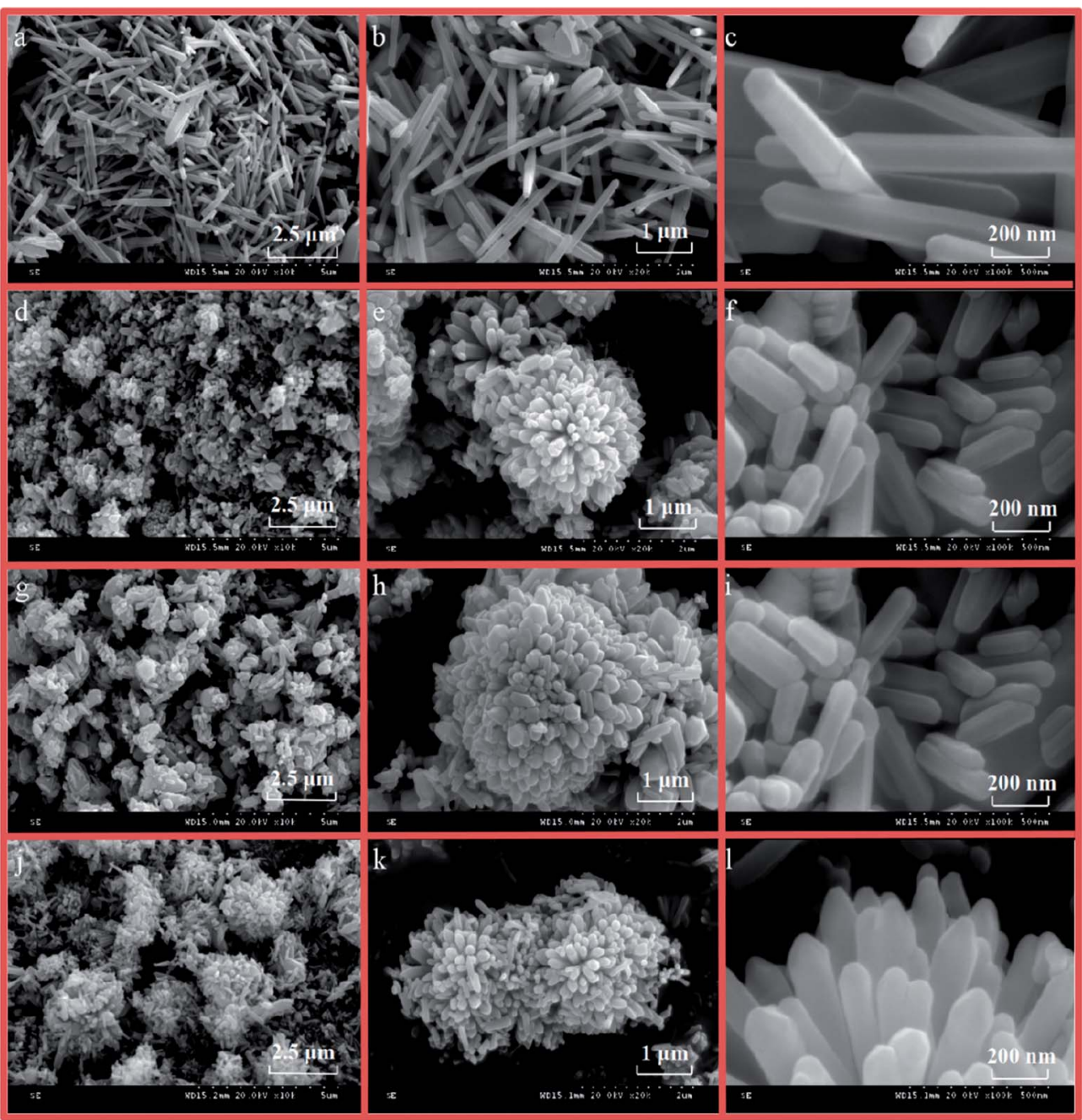

Fig. 4 SEM images of $\mathrm{ZnO}(\mathrm{a}-\mathrm{c}), \mathrm{Ag} / \mathrm{ZnO}-3 \mathrm{~h}(\mathrm{~d}-\mathrm{f}), \mathrm{Ag} / \mathrm{ZnO}-4.5 \mathrm{~h}(\mathrm{~g}-\mathrm{i})$, and $\mathrm{Ag} / \mathrm{ZnO}-6 \mathrm{~h}(\mathrm{j}-\mathrm{l})$.

area. Therefore, ZnO nanorods were more observed at HRTEM detection. In addition, the TEM results show that there are no other particles on the surface of $\mathrm{ZnO}$, showing that $\mathrm{Ag}$ is clearly nucleated at the center of the composite material. In addition, because the size of the $\mathrm{ZnO}$ nanorods is larger, the $\mathrm{Ag}$ nucleus under this degree of inclusion cannot be detected in the lattice stripe. Simultaneously, we conducted the elemental mapping tests on $\mathrm{Ag} / \mathrm{ZnO}-6 \mathrm{~h}$ samples (see Fig. 6). It was found that there is indeed the existence of $\mathrm{Ag}$; however, due to the large size of the $\mathrm{ZnO}$ nanorods, the $\mathrm{Ag}$ nucleus is not easy to be detected. In addition, in the element mapping results, the upper left image in Fig. 6d shows a region with a large amount of $\mathrm{Ag}$ elements. In the corresponding SEM photo (Fig. 6a), the region is a blank area; we postulate that there may be a naked $\mathrm{Ag}$ nucleus that is not covered by $\mathrm{ZnO}$ as its size is too small to be clearly observed in the SEM.

\section{5. $\quad \mathbf{N}_{2}$ adsorption desorption measurement}

To investigate the surface physiochemical properties of the nanocomposites $\mathrm{Ag} / \mathrm{ZnO}$ prepared by microwave-assisted hydrothermal synthesis, $\mathrm{N}_{2}$ adsorption-desorption measurements were performed and compared to those of ZnO. Fig. 7a and b represent the $\mathrm{N}_{2}$ adsorption-desorption isotherm and pore size distribution plot of $\mathrm{ZnO}$ and $\mathrm{Ag} / \mathrm{ZnO}-6 \mathrm{~h}$, respectively, considering that the isotherms and pore size distribution plots of $\mathrm{Ag} / \mathrm{ZnO}-3 \mathrm{~h}$ and $\mathrm{Ag} / \mathrm{ZnO}-4.5 \mathrm{~h}$ were very similar to that of $\mathrm{Ag} / \mathrm{ZnO}-6 \mathrm{~h}$. The $\mathrm{N}_{2}$ adsorption-desorption isotherms of $\mathrm{ZnO}$ and $\mathrm{Ag} / \mathrm{ZnO}-6 \mathrm{~h}$ exhibit a typical type IV pattern according to the classification of IUPAC; $;^{31}$ this type of composite shows a hysteresis loop of type-H3. Moreover, the formation of the hysteresis loop should be related to the capillary condensation phenomenon in the mesoporous materials. We also found that the hysteresis loop of the product significantly shrunk after doping with the noble metal $\mathrm{Ag}$ under microwave irradiation, indicating that the desorption mechanism of the product was correspondingly altered by changes in the synthesis conditions. ${ }^{32}$

Moreover, the BET specific surface area and pore volumes of the products are shown in Table 1, indicating that the BET specific surface area and the pore volume of $\mathrm{Ag} / \mathrm{ZnO}$ increased to varying degrees as compared to that of $\mathrm{ZnO}$. The average pore diameters decreased slightly, indicating that the surface physiochemical properties of the composites prepared by microwave irradiation were effectively improved. Because 


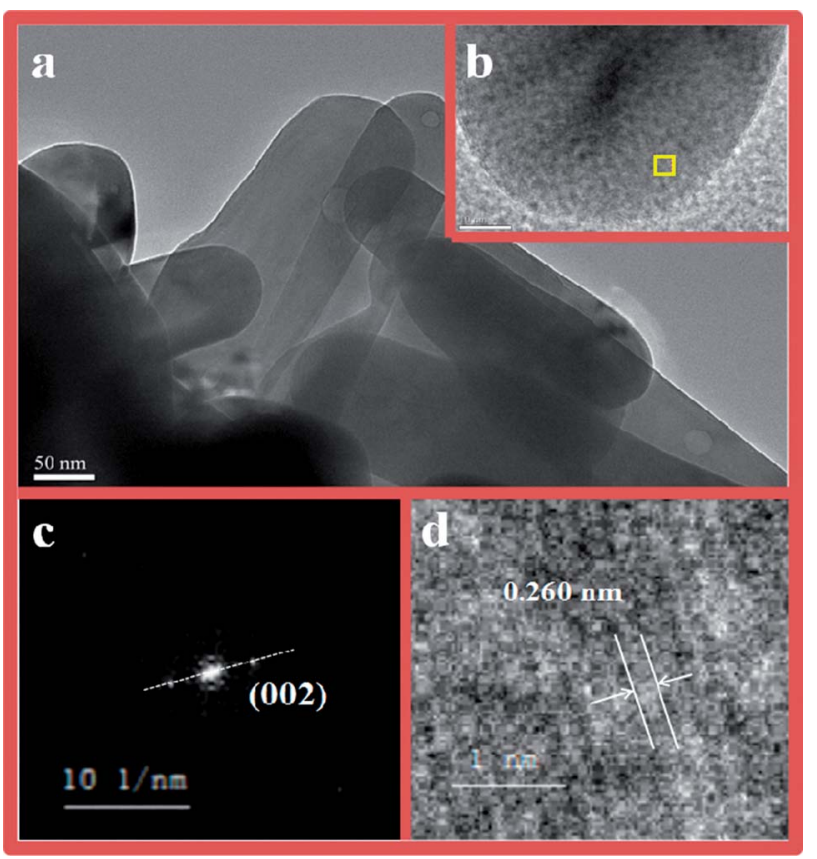

Fig. 5 Results of the TEM image (a) and HRTEM analysis (b-d) of Ag/ $\mathrm{ZnO}-6 \mathrm{~h}$.

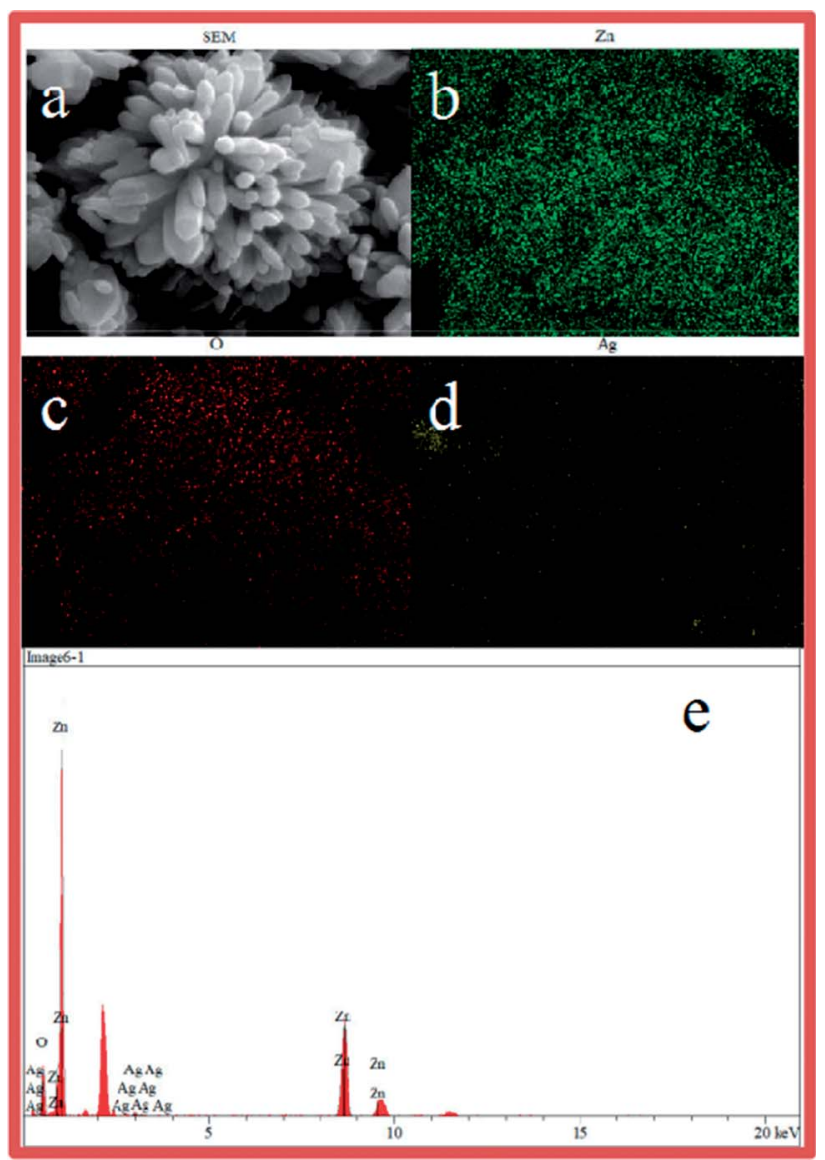

Fig. 6 Element mapping images of Ag/ZnO. (a) SEM, (b) $\mathrm{Zn}$, (c) O, (d) $\mathrm{Ag}$ and (e) EDS spectroscopy of $\mathrm{Ag} / \mathrm{ZnO}$ composites. a higher BET surface area can provide a more active component, microwave-assisted synthesis can improve the photocatalytic activity of composite materials to some extent.

\subsection{Photocatalytic activity of $\mathrm{Ag} / \mathrm{ZnO}$}

To investigate the photocatalytic properties of the assynthesized $\mathrm{Ag} / \mathrm{ZnO}$ composites, photocatalytic tests were performed with $\mathrm{RhB}$ as the model molecule under ultraviolet light. The plots in Fig. 8a show that Ag/ZnO-6h exhibited the highest photocatalytic activity, which was significantly higher than those of other photocatalytic systems. In this study, we generated a reaction kinetic diagram to clearly understand the effects of different conditions on the degradation of RhB (Fig. 8b) using the formula $1 / C=k t+b$, where $C$ is the ratio of the concentration after RhB degradation at time $t$ and the initial concentration and $k$ is the rate constant $\left(\mathrm{min}^{-1}\right)$. Fig. $8 \mathrm{~b}$ shows a linear relationship between $1 / C$ and reaction time $t$, indicating that the degradation of RhB obeys pseudo-second-order kinetics. The apparent reaction rate constants for direct photolysis, P25, $\mathrm{ZnO}, \mathrm{Ag} / \mathrm{ZnO}-3 \mathrm{~h}, \mathrm{Ag} / \mathrm{ZnO}-4.5 \mathrm{~h}$, and $\mathrm{Ag} / \mathrm{ZnO}-6 \mathrm{~h}$ were 0.00716 , $0.00742,0.03463,0.05406,0.07538$, and $0.17136 \mathrm{~min}^{-1}$, respectively. Therefore, the order of photocatalytic activity is $\mathrm{Ag} / \mathrm{ZnO}-6 \mathrm{~h}>\mathrm{Ag} / \mathrm{ZnO}-4.5 \mathrm{~h}>\mathrm{Ag} / \mathrm{ZnO}-3 \mathrm{~h}>\mathrm{ZnO}>\mathrm{P} 25>$ direct photolysis, which is consistent with the activity order of direct photolysis by ultraviolet radiation and the degradation of RhB by different catalysts.

The photocatalytic degradation experiments of dyes of different structures with $\mathrm{Ag} / \mathrm{ZnO}-6 \mathrm{~h}$ as the catalyst were performed under ultraviolet light to investigate the universality of degradation as shown in Fig. 8c. The concentration of four types of dyes gradually decreased by ultraviolet degradation on increasing the reaction time; the degradation rate of $\mathrm{RhB}$, methyl orange, methylene blue, and crystal violet were $93.44 \%$, $84.26 \%, 99.47 \%$, and $97.21 \%$, respectively. Simultaneously, the structure of the four types of organic compounds showed distinct differences, belonging to different types, indicating that the $\mathrm{Ag} / \mathrm{ZnO}$ composite had generality for the degradation of dyes with different structures under ultraviolet light.

Moreover, in this study, we further investigated the other photocatalytic activities of $\mathrm{Ag} / \mathrm{ZnO}$, and other modes of photocatalysis were performed in the conditions of simulated sunlight, visible light, and microwave-assisted irradiation as shown in Fig. 8d. As shown in Fig. 8d Ag/ZnO-6h has high degradation activity in ultraviolet and microwave-assisted photocatalysis. This is because the UV light catalysis reaction is more convenient for the delivery of photogenerated carriers and additional photoelectron transfer pathways. In the process of microwave radiation, the emission spectrum of the microwave discharge electrodeless lamp is primarily in the ultraviolet region; although its power is only $15 \mathrm{~W}$, its activity is close to the activity results under the irradiation of the $125 \mathrm{~W}$ high pressure mercury lamp. ${ }^{33}$

Therefore, the prepared $\mathrm{Ag} / \mathrm{ZnO}-6 \mathrm{~h}$ showed higher photocatalytic activity for the photocatalytic conditions in different modes, which can be attributed to the following factors: (1) the doped $\mathrm{Ag}$ can indirectly affect the interfacial charge transfer 

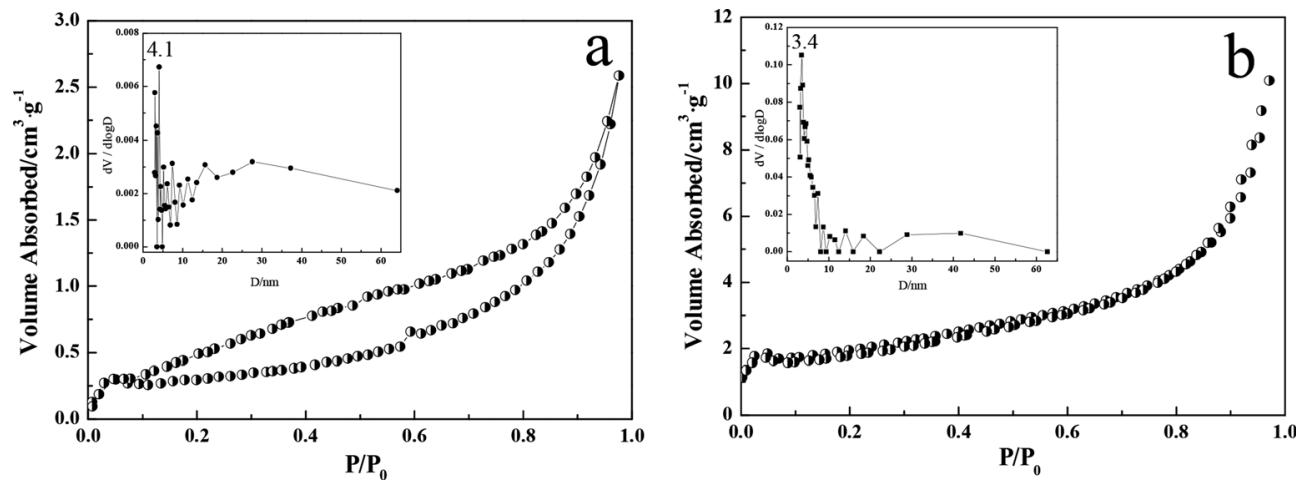

Fig. $7 \quad \mathrm{~N}_{2}$ adsorption-desorption isotherms and pore size distributions (inset) of $\mathrm{ZnO}$ (a) and $\mathrm{Ag} / \mathrm{ZnO}-6 \mathrm{~h}$ (b).

process, and its electron trap effect can inhibit the recombination of photogenerated electron-hole pairs, thus improving the photocatalytic activity of $\mathrm{Ag} / \mathrm{ZnO}$ composite. (2) Under microwave irradiation, the local high temperature produced by the doped noble metal $\mathrm{Ag}$ accelerated the speed of the particle nuclei, resulting in a greater transformation of the particle size and morphology of the products and thus changing their physical properties. Moreover, increasing the BET specific surface area provides more active sites for the reaction. (3) The polarization of microwaves in the microwave-assisted synthesis process leads to the excellent chrysanthemum-like morphology of $\mathrm{Ag} / \mathrm{ZnO}-6 \mathrm{~h}$ samples. (4) Doping with noble metal $\mathrm{Ag}$ promoted the formation of the product and produced a strong absorption in the visible region, increasing the response range of the light absorption of the catalyst, thus effectively enhancing the utilization efficiency of light.

In addition, from the date shown in Fig. 1 and 2, we can find the reason why an increase in $\mathrm{Ag}$ content would improve the photocatalytic properties. On the one hand, with an increase in microwave-synthesis time, the cubic structure of Ag in Ag/ZnO$6 \mathrm{~h}$ was found to be superior to those of other composite materials (Fig. 1). On the other hand, the increase in cubic structure of $\mathrm{Ag}$ shows that the amount of single silver in the composite is significantly greater. The SPR effect of silver increases with an increase in the amount of silver, which improves the absorptive capacity of the visible light of the
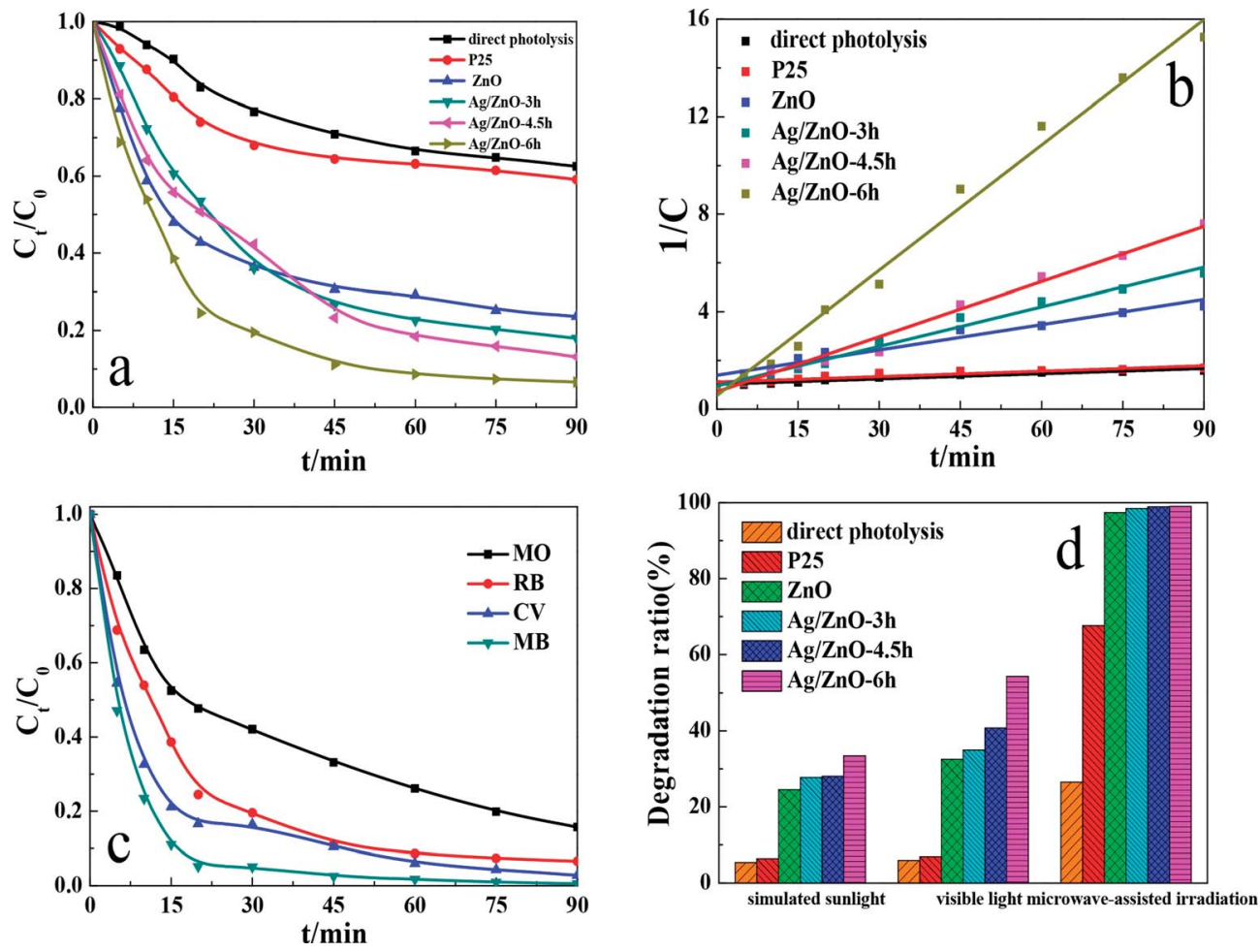

Fig. 8 (a) UV photocatalytic degradation profiles for RhB with different photocatalysts; (b) UV photocatalytic degradation RhB kinetics with different photocatalysts; (c) results of Ag/ZnO-6h UV photocatalytic degradation for different dyes; (d) photocatalytic degradation of RhB profiles with different photocatalysts under different modes. 
composite; therefore, the photocatalytic activity was better than those of the composites synthesized for less time in this study and other reports (see Table 2).

\subsection{Circulation experiment}

The ultraviolet photocatalytic cycle experiments of Ag/ZnO-6h were performed to examine the stability of the photocatalyst. The Ag/ZnO-6h sample was washed several times with ethanol and deionized water, dried, and calcined. The results of the experiments for three cycles of the recycled catalyst are shown in Fig. 9, indicating no significant change in the degradation efficiency of $\mathrm{Ag} / \mathrm{ZnO}-6 \mathrm{~h}$ after the third run. Therefore, Ag/ZnO-6h had a certain stability under ultraviolet light.

\subsection{Photocatalytic hydrogen production}

To compare the photocatalytic hydrogen production capacity of $\mathrm{Ag} / \mathrm{ZnO}$ samples with different microwave irradiation time, photocatalytic hydrogen production with $\mathrm{Ag} / \mathrm{ZnO}-6 \mathrm{~h}, \mathrm{Ag} / \mathrm{ZnO}-$ $4.5 \mathrm{~h}$ and $\mathrm{Ag} / \mathrm{ZnO}-3 \mathrm{~h}$ were carried out; the results are shown in Fig. 10. As shown in Fig. 10, the abilities of photocatalytic hydrogen production of samples prepared under different synthesis times are slightly different and the hydrogen production of $\mathrm{Ag} / \mathrm{ZnO}-6 \mathrm{~h}$ is the highest, indicating the effect of the excellent morphology of the catalyst on photolytic hydrogen production. The above results show that the hydrogen production performance of the as-prepared $\mathrm{Ag} / \mathrm{ZnO}-6 \mathrm{~h}$ nanocomposites is vastly superior, which suggests promising application prospects.

\subsection{Possible photocatalytic mechanism}

Reactive species trapping experiments were performed to investigate the possible reactive oxygen species in the photocatalytic process..$^{37-39}$ In this study, three different chemicals, $p$ benzoquinone (BZQ, a $\cdot \mathrm{O}_{2}^{-}$radical scavenger), disodium ethylenediaminetetraacetate ( $\mathrm{Na}_{2}$-EDTA, a hole scavenger), and methanol ( $\mathrm{MeOH}, \mathrm{a} \cdot \mathrm{OH}$ radical scavenger) were employed and the results are shown in Fig. 9.

Fig. 11 shows that the photocatalytic activity of RhB clearly decreased after adding $\mathrm{MeOH}$, and the degradation rate decreased from $93.44 \%$ to $13.03 \%$, indicating that $\cdot \mathrm{OH}$ was the active species in the photocatalytic process. Moreover, the degradation rate of $\mathrm{RhB}$ decreased to $72.13 \%$ and $57.66 \%$ after adding $\mathrm{Na}_{2}$-EDTA and BZQ, respectively, indicating that $\mathrm{h}^{+}$and $\cdot \mathrm{O}_{2}{ }^{-}$also had an important role in the photodegradation of RhB.

Table 2 Comparison of the degradation rate of dyes with different $\mathrm{Ag} / \mathrm{ZnO}$ catalysts

\begin{tabular}{llll}
\hline Sample & Dye & Degradation rate & Ref. \\
\hline $\mathrm{Ag} / \mathrm{ZnO}-6 \mathrm{~h}$ & $\mathrm{RhB}$ & $94 \%$ & This work \\
$\mathrm{Ag} / \mathrm{ZnO}-1 \mathrm{FAZ}$ & $\mathrm{RhB}$ & $90.2 \%$ & 34 \\
$\mathrm{PC}-\mathrm{Ag}_{10 \%} / \mathrm{ZnO}_{90 \%}$ & $\mathrm{RhB}$ & About $79 \%$ & 35 \\
$\mathrm{ZnO}$ aAg & $\mathrm{MB}$ & About $65 \%$ & 36
\end{tabular}

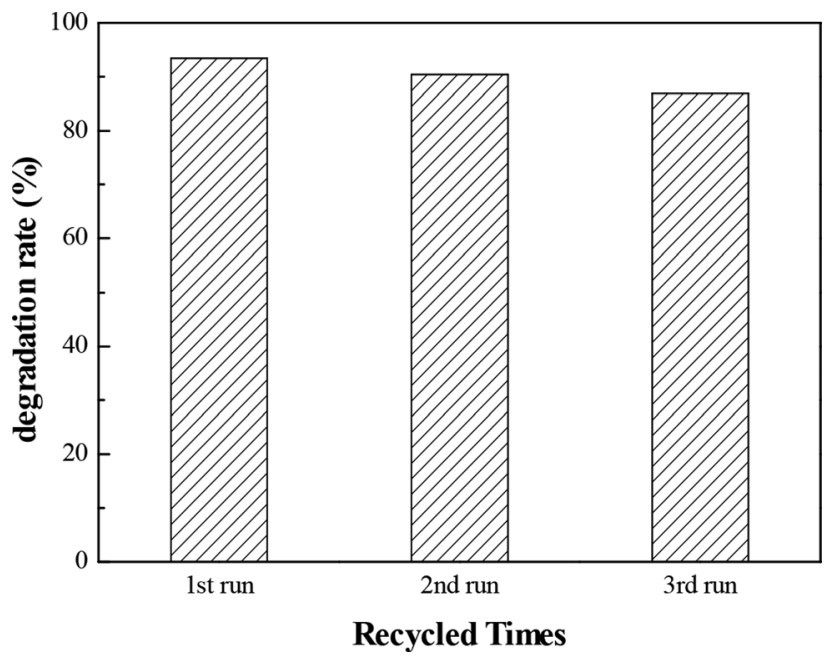

Fig. 9 The recycling use results of $\mathrm{Ag} / \mathrm{ZnO}-6 \mathrm{~h}$ under UV photocatalytic degradation.

Based on the above conclusions, we postulate a possible photocatalytic mechanism of $\mathrm{Ag} / \mathrm{ZnO}$ under different light sources. As shown in Fig. 12a, when the catalyst is irradiated with ultraviolet light, the electrons in the valence band (VB) are excited to the conduction band (CB) as the photon energy is larger than or equal to the band gap energy of $\mathrm{ZnO}$. Moreover, the same number of holes $\left(\mathrm{h}^{+}\right)$is generated in the valence band. As shown in Fig. 12a, the electrons in the conduction band move from the semiconductor $\mathrm{ZnO}$ to $\mathrm{Ag}$ because of the lower Fermi level of Ag. In addition, Ag nanoparticles as electron traps not only reduce the recombination of photogenerated electron-hole pairs, but also prolong the retention time of the photogenerated electrons, thus improving the photocatalytic activity of the composites. Subsequently, an electron acceptor such as $\mathrm{O}_{2}$ can easily trap photogenerated electrons to form superoxide radical anions $\left(\cdot \mathrm{O}_{2}{ }^{-}\right)$; also, photogenerated holes react with the surface $\cdot \mathrm{OH}$

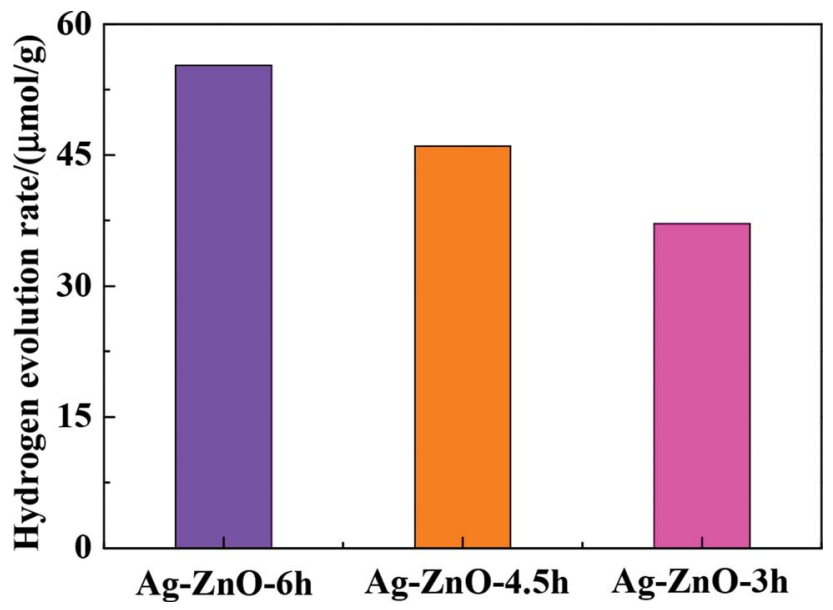

Fig. 10 Hydrogen production results of photolysis of $\mathrm{Ag} / \mathrm{ZnO}$ samples with different microwave synthesis time. 


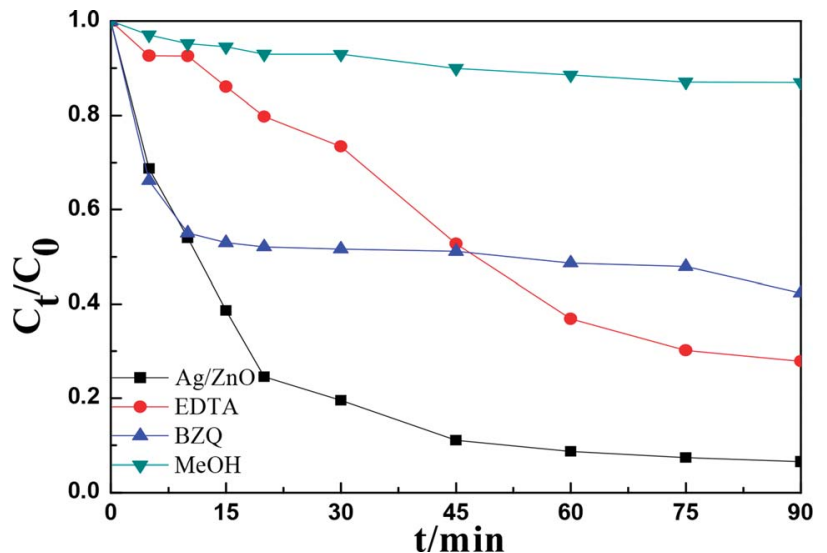

Fig. 11 Reactive species trapping experiments of the $\mathrm{Ag} / \mathrm{ZnO}-6 \mathrm{~h}$ composite.

to produce hydroxyl radicals $(\cdot \mathrm{OH})$, which have a powerful oxidation ability to degrade organic molecules. ${ }^{40,41}$ Simultaneously, the conduction band position of $\mathrm{Ag} / \mathrm{ZnO}-6 \mathrm{~h}$, calculated as $-0.83 \mathrm{eV}$ by the formula $E_{\mathrm{CB}}=X-E_{\mathrm{C}}-0.5 E_{\mathrm{g}}$, is more negative than the hydrogen electrode reaction potential $(0.0 \mathrm{eV} v s$. NHE), such that the conduction band electrons can reduce water to produce hydrogen. The $\mathrm{VB}$ of $\mathrm{ZnO}$ is $2.89 \mathrm{eV}$, which is more positive than those of $\cdot \mathrm{OH} / \mathrm{H}_{2} \mathrm{O}(2.27 \mathrm{eV})$ and $\mathrm{OH}^{-} / \cdot \mathrm{OH}(1.99 \mathrm{eV})$; hence, $\mathrm{OH}^{-}$can be oxidized to $\cdot \mathrm{OH}$ by holes. Together with the electrons transferred from $\mathrm{Ag}$, this results in more electrons reacting with $\mathrm{O}_{2}$, generating a large amount of superoxide radicals $\left(\cdot \mathrm{O}_{2}{ }^{-}\right)$. In addition, $\mathrm{O}_{2}$ is reduced to $\cdot \mathrm{O}_{2}{ }^{-}$under the action of the electrons from the $\mathrm{CB}$ of $\mathrm{ZnO} .{ }^{42}$
Fig. 12b exhibits the speculated photocatalytic mechanism for $\mathrm{Ag} / \mathrm{ZnO}$ illumination with visible light. $\mathrm{ZnO}$ barely absorbs visible light because of its wide band gap $(3.21 \mathrm{eV})$ and it almost does not produce holes and electrons. $\mathrm{Ag} / \mathrm{ZnO}$ displays a drastically reinforced photocatalytic performance in contrast to pure samples under visible light. SPR effect of $\mathrm{Ag}$ nanoparticles is the main reason. Because of the SPR effect of the metallic $\mathrm{Ag}, \mathrm{Ag} / \mathrm{ZnO}$ can respond to visible light $(550 \mathrm{~nm})$ to produce hot plasmonic electrons, which can transfer to the $\mathrm{CB}$ of $\mathrm{ZnO}$. In order to recover to the primal state, Ag needs to accept electrons from the VB of ZnO. The above factors can increase charge carrier lifetimes and depress the recombination of holes and electrons. In addition, the near-field resonant energy transfer of $\mathrm{Ag}$ could accelerate the production and separation of hole-electron pairs in ZnO.

Furthermore, as shown in Fig. 12c, under the irradiation of UV + vis light, the hot plasmonic electrons of $\mathrm{Ag}$ can be transformed to the $\mathrm{CB}$ of $\mathrm{ZnO}$, thus improving the $\mathrm{H}_{2}$ production rate. $\mathrm{Ag}$ nanoparticles play two roles in this photocatalytic system. The first is to transfer electrons to the surface of $\mathrm{ZnO}$ and then react with $\mathrm{H}^{+}$in water to produce hydrogen. The other is that the Ag surface plasmon photogenerated electrons can be injected into the $\mathrm{CB}$ of $\mathrm{ZnO}$ to improve the separation of electrons and holes. Therefore, this can not only improve the absorption of visible light, but also reduce the recombination probability of the photogenerated electron-hole pair, thus improving the photocatalytic activity of hydrogen production. ${ }^{43}$

\section{Conclusions}

A series of chrysanthemum-like composites $\mathrm{Ag} / \mathrm{ZnO}$ were prepared via microwave-assisted hydrothermal synthesis. Due

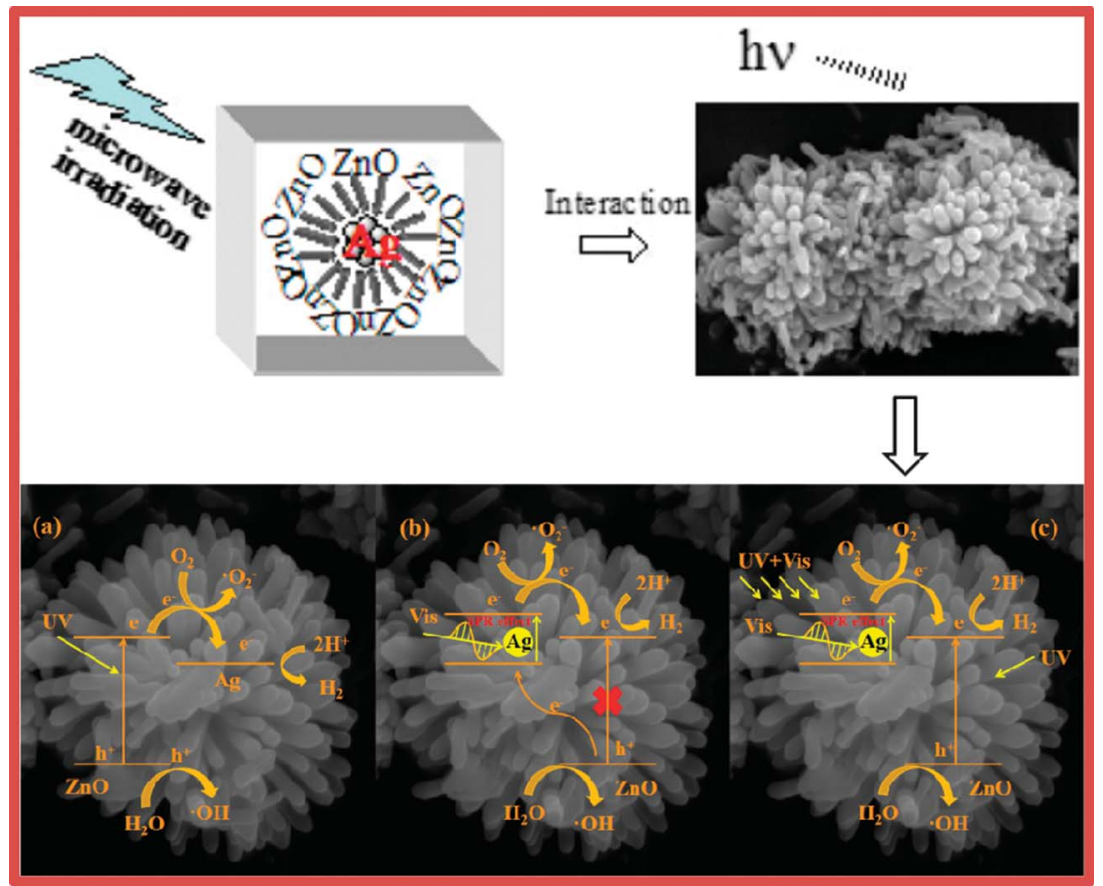

Fig. 12 The possible photocatalytic mechanism of the Ag/ZnO composite. (a) UV light, (b) visible light, and (c) UV + vis light. 
to the strong polarization of microwave irradiation, the intensity of optical absorption of the composites increased and the morphology improved, thus improving the surface physiochemical properties of the composites. Simultaneously, the crystallite size of the composites significantly increased, the band gap energies of the composites slightly reduced, and the arrangement of the shapes of the composites became more regular and ordered on increasing the microwave irradiation time, indicating that increasing microwave irradiation time was conducive to the growth of crystals. Moreover, in the experimental study of multi-mode photocatalytic degradation of RhB and photocatalytic hydrogen production, $\mathrm{Ag} / \mathrm{ZnO}-6 \mathrm{~h}$ composites show good photocatalytic performance, which is due to the following factors: the doping of noble metal $\mathrm{Ag}$ increases the light absorption response range of the catalyst, while its role in the electron trap inhibited the recombination of photogenerated electrons and holes. In contrast, sufficient microwave radiation time promoted the ordered growth of crystals and improved the physiochemical properties.

\section{Conflicts of interest}

There are no conflicts to declare.

\section{Acknowledgements}

The project was supported by the National Natural Science Foundation of China (21376126, 21776144), the Natural Science Foundation of Heilongjiang Province, China (B201106), Scientific Research of Heilongjiang Province Education Department, China (135209105), the Government of Heilongjiang Province Postdoctoral Grants, China (LBH-Z11108), Postdoctoral Researchers in Heilongjiang Province of China Research Initiation Grant Project (LBH-Q13172) and Innovation Project of Qiqihar University Graduate Education (YJSCX2016-ZD10).

\section{References}

1 S. Balachandran and M. Swaminathan, J. Phys. Chem. C, 2012, 116, 26306-26312.

2 T. Lee, V. D. Le, D. Lim, Y. C. Lin, G. M. Morris, A. L. Wong, A. J. Olson, J. H. Elder and C. H. Wong, J. Am. Chem. Soc., 1999, 121, 1145-1155.

3 R. Asahi, T. Morikawa, T. Ohwaki, K. Aoki and Y. Taga, Science, 2001, 293, 269-271.

4 Z. G. Zou, J. H. Ye, K. Sayama and H. Arakawa, Nature, 2001, 414, 625-627.

5 D. H. Yoo, T. V. Cuong, V. H. Luan, N. T. Khoa, E. J. Kim, S. H. Hur and S. H. Hahn, J. Phys. Chem. C, 2012, 116, 7180-7184.

6 P. Periyat, S. C. Pillai, D. E. McCormack, J. Colreavy and S. J. Hinder, J. Phys. Chem. C, 2008, 112, 7644-7652.

7 W. Wu, S. F. Zhang, X. H. Xiao, J. Zhou, F. Ren, L. L. Sun and C. Z. Jiang, ACS Appl. Mater. Interfaces, 2012, 4, 3602-3609.

8 P. L. Zhang, S. Yin and T. Sato, Appl. Catal., B, 2009, 89, 118122.
9 D. Sharma, S. Sharma, B. S. Kaith, J. Rajput and M. Kaur, Appl. Surf. Sci., 2011, 257, 9661-9672.

10 L. F. Gou, M. Chipara and J. M. Zaleski, Chem. Mater., 2007, 19, 1755-1760.

11 A. G. Whittaker and D. M. P. Mingos, J. Chem. Soc., 2000, 1521-1526.

12 H. Q. Wu, Q. Y. Wang, Y. Z. Yao, C. Qian, X. J. Zhang and X. W. Wei, J. Phys. Chem. C, 2008, 112, 16779-16783.

13 Ma. De Lourdes Ruiz Peralta, U. Pal and R. Sánchez Zeferino, ACS Appl. Mater. Interfaces, 2012, 4, 4807-4816.

14 C. D. Gu, C. Cheng, H. Y. Huang, T. L. Wong, N. Wang and T. Y. Zhang, Cryst. Growth Des., 2009, 9, 3278-3285.

15 A. Kudo and Y. Miseki, Chem. Soc. Rev., 2009, 38, 253-278.

16 X. B. Chen, S. H. Shen, L. J. Guo and S. S. Mao, Chem. Rev., 2010, 110, 6503-6570.

17 S. Cho, J. W. Jang, S. H. Jung, B. R. Lee, E. Oh and K. H. Lee, Langmuir, 2009, 25, 3825-3831.

18 Y. H. Zheng, L. R. Zheng, Y. Y. Zhan, X. Y. Lin, Q. Zheng and K. M. Wei, Inorg. Chem., 2007, 46, 6980-6986.

19 E. T. Thostenson and T. W. Chou, Composites, Part A, 1999, 30, 1055-1071.

20 Q. Zhu, W. S. Wang, L. Lin, G. Q. Gao, H. L. Guo, H. Du and A. W. Xu, J. Phys. Chem. C, 2013, 117, 5894-5900.

21 D. E. Motaung, G. H. Mhlongo, S. S. Nkosi, G. F. Malgas, B. W. Mwakikunga, E. Coetsee, H. C. Swart, H. M. I. Abdallah, T. Moyo and S. S. Ray, ACS Appl. Mater. Interfaces, 2014, 6, 8981-8995.

22 H. R. Liu, G. X. Shao, J. F. Zhao, Z. X. Zhang, Y. Zhang, J. Liang, X. G. Liu, H. S. Jia and B. S. Xu, J. Phys. Chem. C, 2012, 116, 16182-16190.

23 V. V. Atuchin, E. N. Galashov, O. Y. Khyzhun, A. S. Kozhukhov, L. D. Pokrovsky and V. N. Shlegel, Cryst. Growth Des., 2011, 11, 2479-2484.

24 S. L. Shen, J. Zhuang, X. X. Xu, A. Nisar, S. Hu and X. Wang, Inorg. Chem., 2009, 48, 5117-5128.

25 Y. H. Zheng, C. Q. Chen, Y. Y. Zhan, X. Y. Lin, Q. Zheng, K. M. Wei and J. F. Zhu, J. Phys. Chem. C, 2008, 112, 10773-10777.

26 S. H. Su, J. H. Lai, H. H. Chen, T. H. Lee, Y. J. Hu, R. L. Wang and J. C. A. Huang, J. Phys. Chem. C, 2012, 116, 9917-9924.

27 J. Polte, T. T. Ahner, F. Delissen, S. Sokolov, F. Emmerling, A. F. Thünemann and R. Kraehnert, J. Am. Chem. Soc., 2010, 132, 1296-1301.

28 G. Yang, Y. Kong, W. Hou and Q. Yan, J. Phys. Chem. B, 2005, 109, 1371-1379.

29 S. A. Freeman, J. H. Booske and R. F. Cooper, Phys. Rev. Lett., 1995, 74, 2042-2045.

30 S. A. Ansari, M. M. Khan, M. O. Ansari, J. Lee and M. H. Cho, J. Phys. Chem. C, 2013, 117, 27023-27030.

31 K. S. W. Sing, D. H. Everett, R. A. W. Haul, L. Moscuo, R. A. Pierotti, J. Rouquerol and T. Siemieniewska, Pure Appl. Chem., 1985, 57, 603-619.

32 K. Morishige and M. Ishino, Langmuir, 2007, 23, 1102111026.

33 U. Riaz and S. M. Ashraf, RSC Adv., 2014, 4, 47153.

34 M. H. Sarvari, T. A. Kachouei and F. Moeini, RSC Adv., 2015, 5, 9050-9056. 
35 Q. Zhang, J. K. Liu, J. D. Wang, H. X. Luo, Y. Lu and X. H. Yang, Ind. Eng. Chem. Res., 2014, 53, 13236-13246.

36 M. X. Liu, S. Z. Su, Y. M. Li, X. W. Song, F. Yu, X. W. Ding, H. B. Xin and X. L. Wang, ACS Sustainable Chem. Eng., 2017, 5, 5651-5656.

37 J. Z. Li, J. B. Zhong, X. Y. He, S. T. Huang, J. Zeng, J. J. He and W. L. Shi, Appl. Surf. Sci., 2013, 28, 527-532.

38 X. F. Yang, H. Y. Cui, Y. Li, J. L. Qin, R. X. Zhang and H. Tang, ACS Catal., 2013, 3, 363-369.
39 C. S. Pan and Y. F. Zhu, Environ. Sci. Technol., 2010, 44, 55705574.

40 L. Wu, J. C. Yu and X. Z. Fu, J. Mol. Catal. A: Chem., 2006, 244, 25-32.

41 S. Cho, J. W. Jang, J. Kim, J. S. Lee, W. Y. Choi and K. H. Lee, Langmuir, 2011, 27, 10243-10250.

42 F. Chen, H. W. Huang, C. Zeng, X. Du and Y. H. Zhang, ACS Sustainable Chem. Eng., 2017, 5, 7777-7791.

43 H. Q. Gao, P. Zhang, J. T. Zhao, Y. S. Zhang, J. H. Hu and G. S. Shao, Appl. Catal., B, 2017, 210, 297-305. 